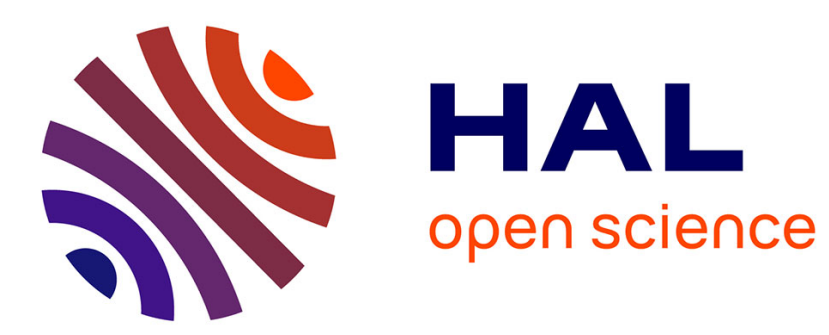

\title{
Strategic Portfolios for the Integral Design of Value-Added Networks
}

\author{
Paul Schönsleben, Manuel Rippel
}

\section{To cite this version:}

Paul Schönsleben, Manuel Rippel. Strategic Portfolios for the Integral Design of Value-Added Networks. IFIP International Conference on Advances in Production Management Systems (APMS), Sep 2016, Iguassu Falls, Brazil. pp.189-197, 10.1007/978-3-319-51133-7_23 . hal-01615712

\section{HAL Id: hal-01615712 \\ https://hal.inria.fr/hal-01615712}

Submitted on 12 Oct 2017

HAL is a multi-disciplinary open access archive for the deposit and dissemination of scientific research documents, whether they are published or not. The documents may come from teaching and research institutions in France or abroad, or from public or private research centers.
L'archive ouverte pluridisciplinaire HAL, est destinée au dépôt et à la diffusion de documents scientifiques de niveau recherche, publiés ou non, émanant des établissements d'enseignement et de recherche français ou étrangers, des laboratoires publics ou privés. 


\title{
Strategic Portfolios for the Integral Design of Value-added Networks
}

\author{
Paul Schönsleben ${ }^{1}$ and Manuel Rippel ${ }^{2}$ \\ 1 ETH Zürich, BWI Centerfor Industrial Management, Zurich, Switzerland \\ pschoensleben@ethz.ch \\ 2 Chairman of the Board of the A. Vogel / Bioforce Group, Switzerland
}

\begin{abstract}
An adequate decision method plays an important role in strategic location planning, especially for physical goods. After a breakdown of the value-added network into its natural components, this paper uses strategic portfolios for determining the different network designs. The portfolios depend on generic market, product and service featuresand fit together. The combination of the single portfolios represents the design options of the integral value-added network.
\end{abstract}

Keywords: Strategic management $\cdot$ Value-added network design $\cdot$ Portfolios.

\section{Importance of Portfolios for Strategic Planning}

In practice, managers in firms like to base their strategic decisions on simple approaches that provide intuitive transparency and allow assessment of the robustness of the solution. Portfolios correspond to such an approach. In fact, most human beings intuitively understand logical relations if these are expressed in two dimensions, e.g. on a piece of paper, where both the horizontal and the vertical dimension stand for features that characterize the issue of the management task. Thus, people within and across companies can obtain a mutual understanding that can entail a successful cooperation.

Decisions to invest in value-added networks are strategic, owing to the high financial commitment and the long lead time until the facilities enter into operation. By using the portfolio approach, $[1,2,3]$, introduce centralized and decentralized production concepts. The adequate concept may differ for each product family.To be feasible in practice, such a decision also involves the determination of the suitable transport, distributionand service concepts. Though,in general, authors of qualitative methods limit their discussion on one type of concept. This paper proposes a portfolio-based approach that allows an integrated determination of value-added networks. It builds on methods for designing production networks in [2,4], distribution networks in [5], and retail, service and transport networks in [6]. The approach first breaks down the network into its natural components. Then, by looking at the properties of the market, the product or the service as generic features, it is possible to combine the values of these features to get a set of portfolios of the design options for the production, transport, 
distribution and service network. This set mutually fits, that is, the combination of the single portfolios represents the design options of the integral value-added network.

\section{Modelling of the Value-added Network at the Strategic Level}

At the strategic level, the value-added network of the vendor has to fulfill the requirements of the consumer. This is true for any kind of product or service, be it for typical consumer goods such as furniture and cars or for investments goods such as machine tool. The Figure 1 shows the typical life-cycle phases of a product at the consumer's site and the classical, natural breakdown into areas of the value-added network of the vendor for the complementing life-cycle phases of the product.

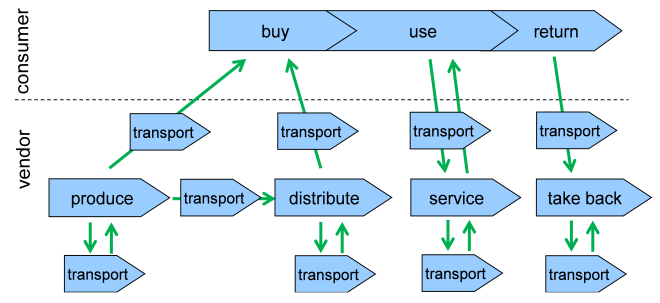

Fig. 1. Breakdown in areas of the value-added network of the vendor in function of the life-cycle phases of the product at the consumer's site.

After design, a product is produced by the vendor or his suppliers. A number of transport processes link the different value-added steps during this life-cycle phase of the product. Subsequently, the product is either transported directlyto the consumer or to a distribution network that finally delivers the product to the consumer via a number of echelons and warehouses Decentralized distribution can include a retail network. Thereby, it is not important whether the vendor possesses the different networks or mandates $3^{\text {rd }}$ party providers for the respective tasks. During the use phase, a service network maintains the product, then called "service object". For this, owned or mandated transport networks pick up and later bring the service object at / to the customer or a collection point. If the product is used up, an adequate network will take back the product from the consumer. As a service network generally can take back products at the end of their use phase, there is no need for a separate network for this task.

\section{Portfolios for the Network Design in Different Areas}

For each area, we explain the strategic portfolio of design options and the underlying conflict of aims by presenting the generic features. Due to space restriction, 
the Section on service network design had to be omitted. The reader is referred to $[6]$.

\subsection{Production Network Design}

As a point of departure, and in order to introduce terminology, Figure 2, copied from [2] (see also the adaption in [3]), shows more centralized or decentralized design options between two (conflicting) dimensions, taking the example of a product with four operations (or production levels) and subsequent distribution.

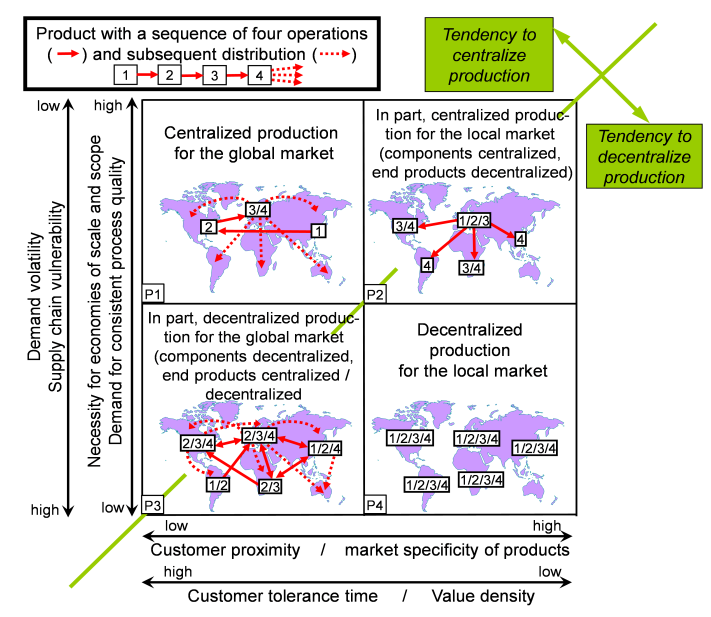

Fig. 2. Features of and design options for production networks (adapted from [2,4])

Figure 2 shows two times four generic features for designing production networks. In the x-axis, these are a) Customer proximity:To sell a product it can be necessary to locate the value-adding processes close to the customers; b) Market specificity of products: Adapting to the market is essential for functional requirements or for the appearance; c) Customer tolerance time: After [7], this is the time span the customer will (or can) tolerate from the date of the order release to delivery of the product; d) Value density, defined as item costs per kilo or cubic meter: Transport costs are of greater consequence if value density is low than if value density is high.

In the y-axis, the four features are a) Demand volatility: Items have high demand volatility if many periods with no or very little demand are interrupted by few periods with large demand, for example ten times higher, often without recognizable regularity; b) Supply chain vulnerability: Disruptions can arise from either the supply chain partners or the macro-economic environment; c) Necessity for economies of scale: Are the manufacturing costs of the product low enough? d) Demand for consistent process quality: Can customer needs be satisfied despite 
differing process quality? For more detailed discussion of Figure 2, as well as for industrial examples for the four sectors P1, P2, P3 and P4, see [4] and [2].

\subsection{Transportation Network Design}

Figure 3, copied from [6], shows, in addition to the two classical designs (direct or indirect transport) two possible mixed designs for the transport between two locations L1 and L2. The four possible designs lie in a two-dimensional space, spanned by the dimensions that correspond to two (conflicting) groups of features.

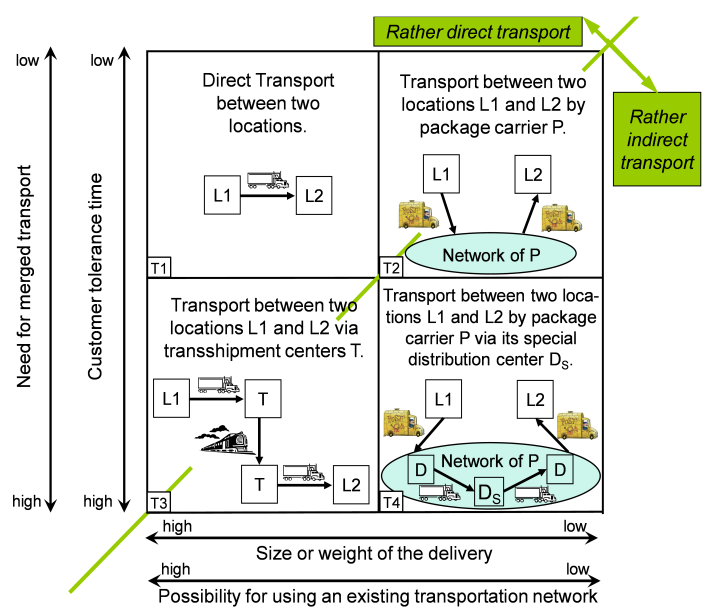

Fig. 3. Features of and design options for transportation networks (taken from [6])

Figure 3 shows two times two generic features for designing transport networks. In the x-axis, these are a) Size or weight of the delivery in kilos or cubic meters: How do the suitable means of transport match up to this? b) Possibility of using an existing transport network: Can the delivery specify a means of transport that is already carrying deliveries between the point of dispatch and the recipient, that is not yet at full capacity, and that has a known and fitting timetable. In the y-axis, the two features are a) Customer tolerance time, as defined in Section 3.1; b) Need for merged transport: To which extent delivery will be made together with products from another manufacturer? In the case of returns, to what extent must several products or parts thereof be sent back to a number of manufacturers at the same time? For detailed discussion of Figure 3, and for industrial examples for the four sectors T1, T2, T3 and T4, see [6].

\subsection{Distribution Network Desig}

Based on an idea in [5] and copied from [6], the portfolio in Figure 4 shows, in addition to the two classical designs (centralized or decentralized distribution) 
two possible mixed designs. The four possible designs lie in a two-dimensional space, spanned by the dimensions that correspond to the two (conflicting) groups of features.

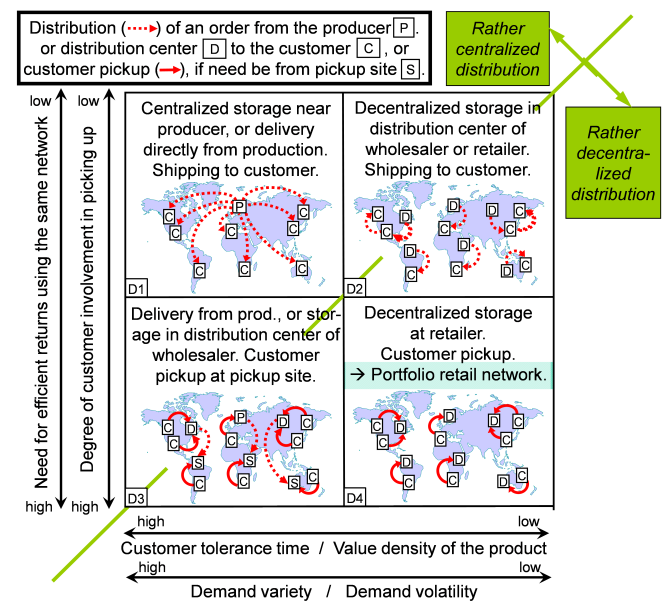

Fig. 4. Features of and design options for distribution networks (taken from [6]).

Figure 4 shows two times four generic features for designing distribution networks. In the x-axis, these are a) Demand volatility, as defined in Section 3.1; b) Demand variety: High demand variety means that customers demand many different products. For these products the demand volatility is mostly high as well; c) Value density, as defined in Section 3.1; d) Customer tolerance time, as defined in Section 3.1. In the case of global distribution, the delivery lead time also includes the time required by customs procedures, which can disadvantage centralized distribution.

In the y-axis, the four features are a) Need for efficient returns using the same network: Is it important that the customer be able to return goods efficiently through the same distribution network and that the network be able to handle these returns efficiently (keyword: reverse logistics)? b) Degree of customer involvement in picking up: To what extent are customers willing and able to picking up the product themselves?

For more detailed discussion of Figure 4, as well as for industrial examples for the four sectors D1, D2, D3 and D4, see [6].

\subsection{Retail Network Design}

For decentralized distribution, in the first approach points of sale (POS) with a smaller volume of goods (i.e. items and/orquantity per item) available at the POS, can be distinguished from those with a larger volume. Copied from [6], Figure 5 shows the resulting design options for retail networks. 


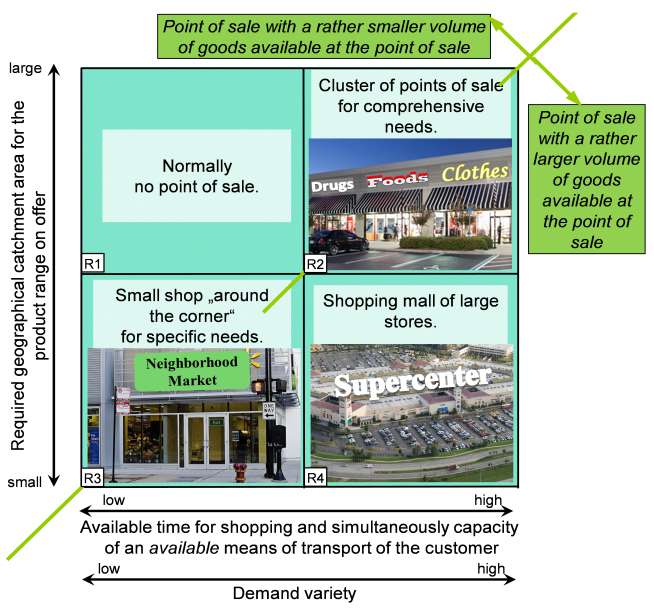

Fig. 5. Decentralized distribution: portfolio for retail network design (taken from [6]).

Figure 5 shows three generic features for designing retail networks. In the x-axis, these are a) Demand variety: as in Section 3.3; b) Available time for shopping and simultaneously capacity of an available means of transport of the customer: For private consumers (B2C), a car has a high capacity. On foot or by bicycle, the capacity is, in contrast, low. If time is limited, or the car is unavailable at the appropriate time, then the purchase option is restricted to a local outlet and limited size and weight. For B2B purchasers - depending on the transaction - a lorry offers high capacity. A small car can then only be used to purchase items of limited size and weight.

In the $\mathrm{y}$-axis, the feature is the required geographical catchment area for the product range on offer: This characteristic assesses the size of the catchment area in which a "sufficient" number of customers are based, for whom the offered product range represents a good fit in terms of product quality and price. This assessment is carried out in consideration of purchasing power, time available and the choice of means of transport. "Sufficient" means that the frequency of purchases multiplied by the average value of each sale corresponds to a minimum sale value per time unit that is required in order to make the operation of the POS a profitable venture.

For more detailed discussion of Figure 5, as well as for industrial examples for the three sectors R2, R3 and R4, see [6]. If efficient returns using the same network are possible, the distribution network can be used for taking back products at the end of their use phase in a natural way.

\section{Integration of the Portfolios}

An adequate design of the value-added network is decisive for customer satisfaction, given a sufficient quality of the delivered product or service. As Figure 6 
shows for the production and the delivery process, the production, distribution, retail (if needed), and various transport networkshave to fit together in order to achieve the goal of a satisfied customer. There are dependencies between the design options of the different portfolios that should be considered for their integration. Here are some examples:

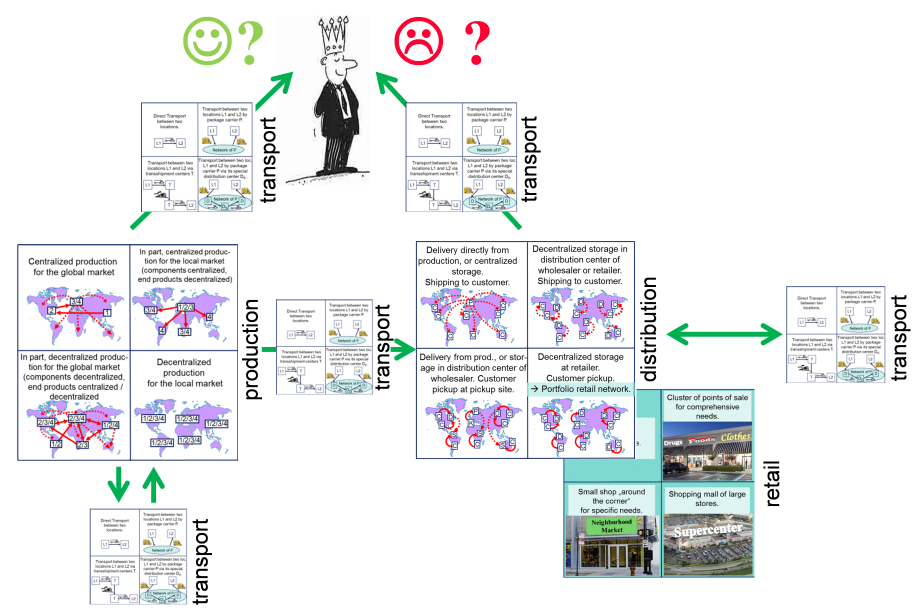

Fig. 6. Interrelation between and integration of the production, transport, distribution and retail network

As the customer tolerance time is a featurefor the design of both transport networks (see Figure 3) as well asproductionand distribution networks (see Figures 2 and 4), there are naturally close combinations when it comes to integrating the networks. This is the case when the customer tolerance time is low in both portfolios, or high in both portfolios. In the case of the distribution network, this means 1.): Decentralized distribution is the preferred combination for direct transport, with the aim of reducing delivery lead time to a minimum; and 2.) Centralized distribution is the preferred combination with indirect transport, since a short delivery lead time is not the priority and it is preferable to ensure that the means of transport is operating at better capacity utilization levels across the route to achieve lower transportation costs.

However, the other combinations are also possible. 1.): If the combination of centralized distribution and direct transport is advantageous, demand is highly varied and/or volatile. The reduced storage costs obtained from centralized warehousing thereby outweigh the disadvantage of a lengthier delivery lead time. Products with high value density allow anyway to select a means of transport that is fast enough. 2.): If the combination of decentralized distribution with indirect transport is advantageous, the ability to reduce transportation costs or increase simplicity of a merged transport (the "in-transit merge" where the 
customer receives just one complete delivery) outweigh the disadvantages of a longer delivery lead time from the customer's perspective.

\section{Conclusions and Outlook}

In addition to existing methods and techniques that generally focus buton one kind of network design, there is a need for a method that allows an integrated determination of the design of the production, transport, distribution, and service network. This paper shows how a portfolio-based approach is a possible solution to this need. After a breakdown of the vendor's value-added network into its natural components, and using generic market and product or service features, potential design options for each area of the value-added networ kwere established. The approach allows a subsequent integration: a combination of designs of the production, distribution, service and transport networks that suits both the product and the targeted customer segment, and that fits well together. At Bioforce we used this approach when integrating the recently acquired Dutch partner company. FDA / GMP and economy-of-scale requirementsled to a centralized production of each product. Yet, decentralized finished-good storage at both production sites speeds up the delivery to the retail network of certain markets and allows continued delivery when issues of customs-clearance between an EU country and Switzerland (Non-EU) arise.

Once a fitting set of value-added networks has been determined, the next thing to do is to start, in each area, the location selection process. Here, factors like political and economic business environment, market attractiveness, or cultural and infrastructure aspects allow a systematic selection of locations. See here [4]. For evaluating potential business partners, techniques like social network analysis (SNA) can be helpful.

\section{References}

1. Abele, E., Meyer, T., Näher, U., Strube, G., Sykes, R. (eds.): Global Production. Springer Berlin Heidelberg, Berlin, Heidelberg (2008)

2. Schönsleben, P.: Changeability of Strategic and Tactical Production Concepts. CIRP Annals - Manufacturing Technology 58(1), 383-386 (2009)

3. Váncza, J., Monostori, L., Lutters, D., Kumara, S., Tseng, M., Valckenaers, P., Van Brussel, H.: Cooperative and Responsive Manufacturing Enterprises. CIRP Annals - Manufacturing Technology 60(2), 797-820 (2011)

4. Schönsleben, P.: Integral Logistics Management: Operations and Supply Chain Management Within and Across Companies. CRC Press, Boca Raton, FL (2016)

5. Chopra, S.: Designing the Distribution Network in a Supply Chain. Transportation Research Part E: Logistics and Transportation Review 39(2), 123-140 (Mar 2003)

6. Schönsleben, P.: Toward the Integrated Determination of a Strategic Production Network Design, Distribution Network Design, Service Network Design, and Transport Network Design for Manufacturers of Physical Products. CRC Press, Boca Raton, FL (2016)

7. Blackstone, J.H., Jonah, J.: APICS Dictionary: The Essential Supply Chain Reference. Chicago, IL: APICS (2013) 